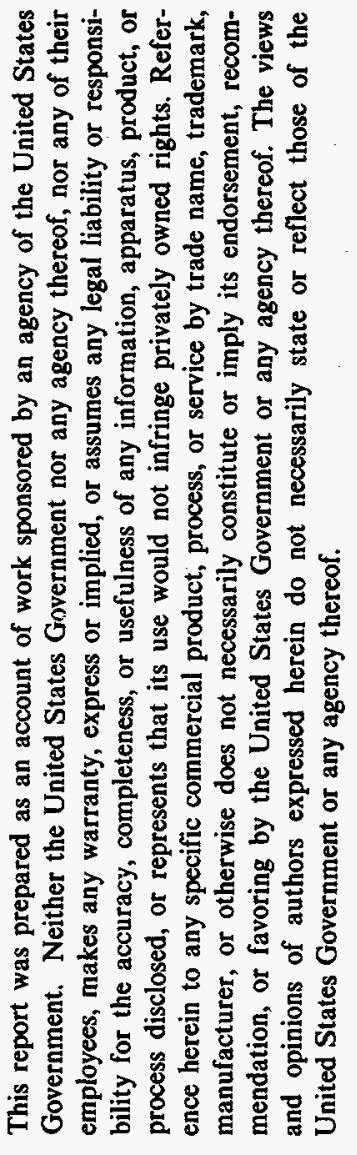

\title{
NUCLEAR AND THERMAL ANALYSIS OF THE HEATPIPE POWER AND BIMODAL SYSTEMS
}

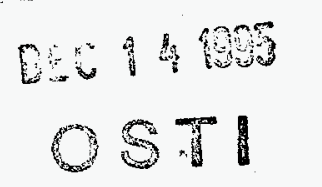

\author{
DAVID I. POSTON \\ MICHAEL G. HOUTS
}

Submitted to:

\section{STAIF-96 MEETING, JANUARY 7-11, 1996, ALBUQUERQUE, NM}

DISTRIBUTION OF THIS DOCUMENT IS UNLIMITED

\section{Los Alamos}

NATIONAL LABORATORY

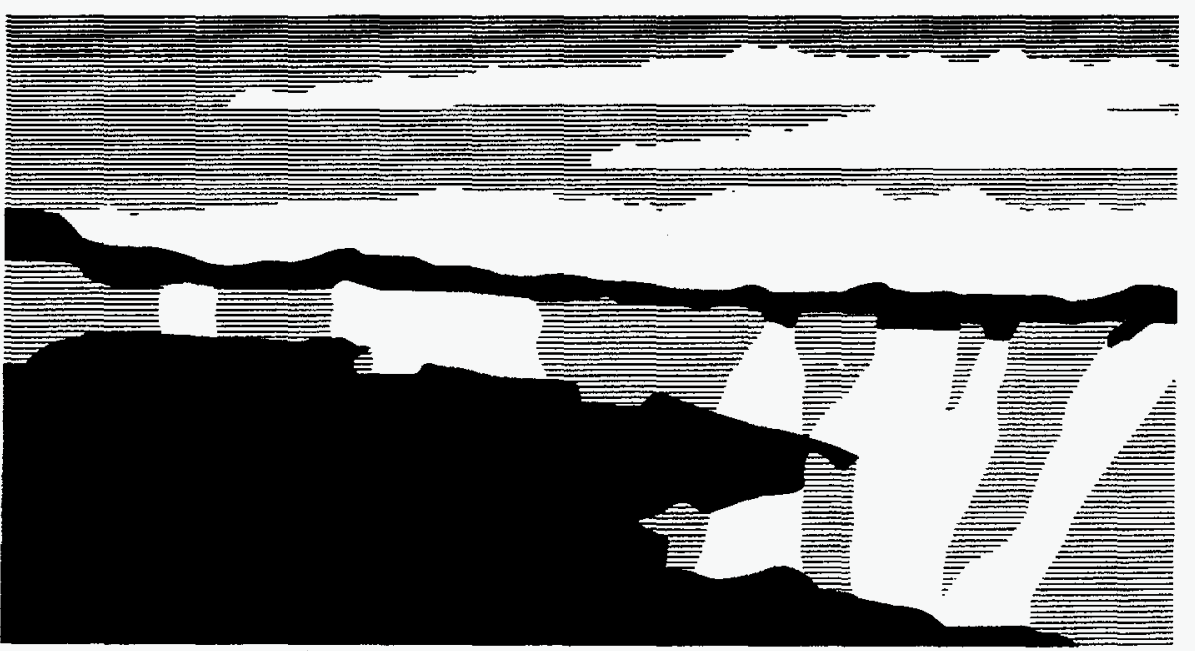

Los Alamos National Laboratory, an affirmative action/equal opportunily empldyer, is operated by the University of California for the U.S. Department of Energy under contract W-7405-ENG-36. By acceptance of this article, the publisher recognizes that the U.S. Government retains a nonexclusive, royalty-free license to publish or reproduce the published form of this contribution, or to allow others to do so, for U.S. Government purposes. The Los Alamos National Laboratory requests that the publisher identify this article as work performed under the auspices of the U.S. Department of Energy. 


\section{DISCLAMMER}

Portions of this document may be illegible in electronic image products. Images are produced from the best available original document. 
NUCLEAR AND THERMAL ANALYSIS OF THE HEATPIPE POWER AND BIMODAL SYSTEMS

\author{
David I. Poston and Michael G. Houts \\ Los Alamos National Laboratory, MS K551 \\ Los Alamos, NM 87545 \\ (505)667-4336/(505) 665-3167 (FAX)
}

\begin{abstract}
This paper discusses the nuclear and thermal analysis of two fission-powered concepts: (1) the Heatpipe Power System (HPS), which provides power only, and (2) the Heatpipe Bimodal System (HBS), which provides both power and thermal propulsion. The HPS and HBS systems can provide substantial levels of power and propulsion at low mass with a high degree of safety and reliability. The systems have been designed to utilize existing technology and facilities, which will make the development cost relatively low.
\end{abstract}

\title{
INTRODUCTION
}

The general approach of the HPS/HBS concepts is to build a system consisting of several identical independent modules. The baseline approach is to bond fuel pins longitudinally to a heatpipe of the same diameter. Power is transferred from the fuel to the heatpipes and then transported via the heatpipes to the power conversion system. The primary purpose of the bonds is to provide thermal contact, although adequate structural support also must be provided. The thermal bond could be provided by: a braze, an electron beam weld, chemical vapor infiltration, hot isostatic pressing, or some other method. As an alternative, the thermal bond could be provided by filling the interstitials between the pins with a conductive fluid or a refractory metal wool. If very small pin diameters are used, then it may be possible to achieve reasonable powers without thermal bonding; thus, only a simple structural bond would be needed.

The HPS and HBS both have 10 important features:

1. Only existing technology and recently tested fuel forms are used.

2. Fuel can be moved separately from the system, greatly facilitating system fabrication and handling.

3. Full electrically heated system testing is poscible in all modes, with minimal operations required $t^{n}$ replace the heaters with fuel and ready the system for launch.

4. The systems are passively subcritical during launch accidents.

5. A modular approach is used, and most technical issues can be resolved with inexpensive module tests.

6. Bonds between dissimilar metals are minimized.

7. There are no single point failures during power mode operation.

8. The fuel burnup rate is quite low to help ensure a $>10$ yr system life.

9. There are no pumped coolant loops, and the systems can be shutdown and restarted without coolant freeze/thaw concerns.

10. A full ground nuclear test is not needed, and development costs will be low.

The versatility of the HPS/HBS design approach allows several design options to be considered. One low-power HPS design uses uranium nitride fuel and SNAP-10A-style thermoelectric power converters to produce $5 \mathrm{kWe}$ at a system mass of $\sim 500 \mathrm{~kg}$. The unicouple thermoelectric converters have a hot-shoe temperature of $1275 \mathrm{~K}$ and reject waste heat at $775 \mathrm{~K}$. This type of converter has been used extensively by the space program, demonstrating an operational lifetime of decades. A core with a larger number of smaller modules (same overall core size) can be used to provide up to $500 \mathrm{kWt}$ to a power conversion subsystem, and a slightly larger core using a higher heatpipe to fuel ratio can provide $>1 \mathrm{MWt}$. The baseline uranium dioxide fueled HBS produces $>50 \mathrm{~N}$ of thrust at a specific impulse $>750 \mathrm{~s}$, can operate for long periods of time in bimodal mode (hundreds of hours, limited by propellant supply), produces $>5 \mathrm{kWe}$ in power or bimodal mode, has $>10$ yr power mode life, and has a mass of $\sim 800 \mathrm{~kg}$. 
A more detailed description of the HPS/HBS approach is given in a companion paper (Houts, 1996). Schematics of an HPS 4-pin module, and the baseline 12-module HPS core are shown in Figures 1 and 2.

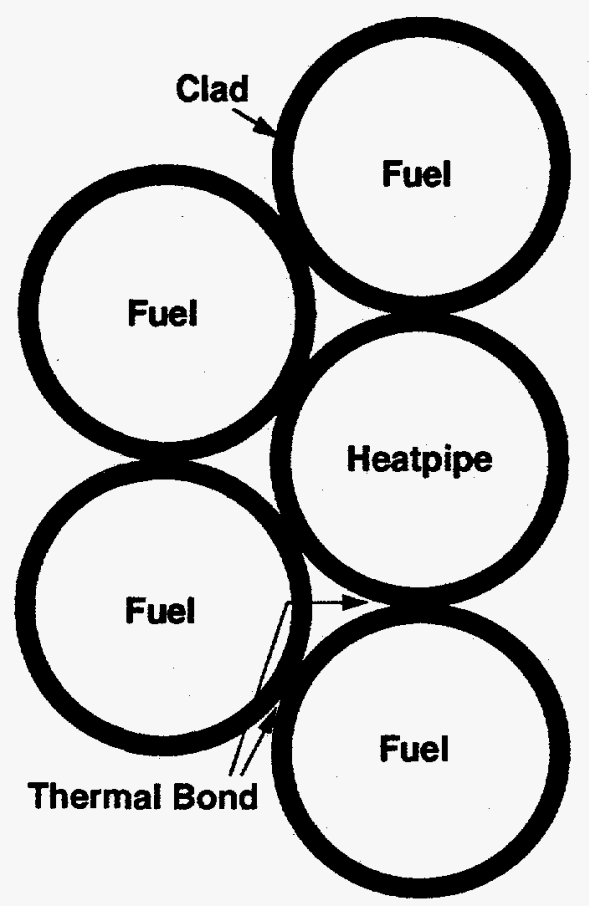

FIGURE 1. HPS 4-Pin Module.

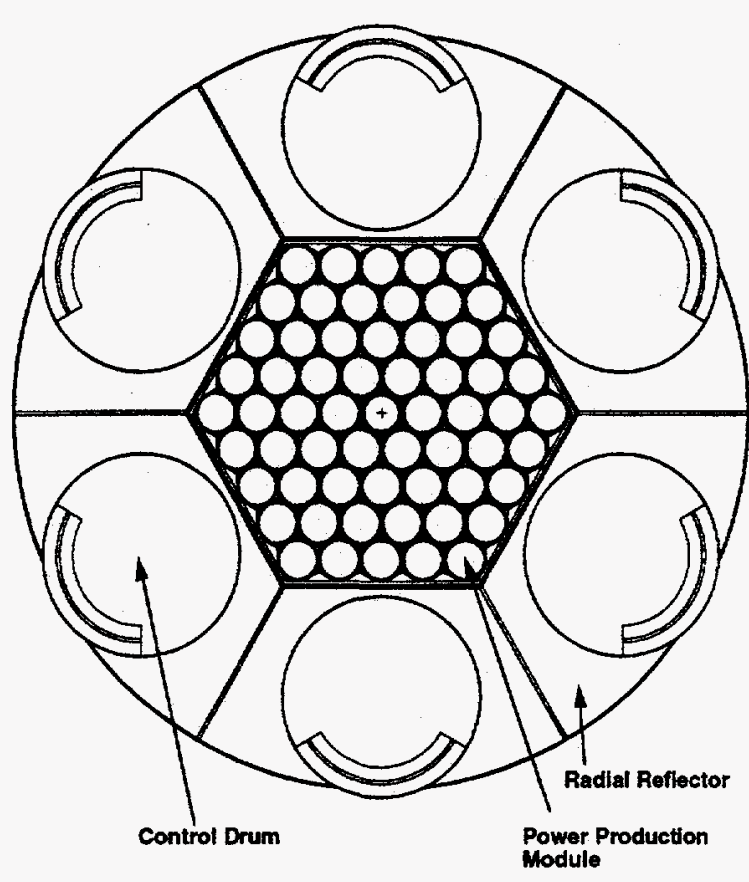

FIGURE 2. 12-Module HPS Schematic.

\section{HPS/HBS MATERIALS}

To gain insight into the nuclear and thermal analysis of the HPS and HBS designs, it is helpful to first discuss the different materials that are considered for each region of the core.

\section{Fuel}

Three fuels are being considered for the baseline HPS/HBS systems - uranium nitride (UN), uranium dioxide $\left(\mathrm{UO}_{2}\right)$, and uranium carbonitride (UCN). Recent test data exist for all three fuels, although the UCN tests have been performed in Russia. Uranium nitride has a very high uranium loading, which results in a low mass core, and makes it a good candidate for applications where low mass is the limiting factor. Uranium dioxide can operate at very high temperatures, making it a good candidate for high power or bimodal applications. Uranium carbonitride has a high uranium loading and the ability to operate at high temperatures, which would make it the best choice for most applications if enough test data are obtained to verify its suitability. For comparison, UN has a theoretical uranium loading $40 \%$ higher than UO2, and in most applications this percentage is even higher because UN usually is used at a higher theoretical density than $\mathrm{UO}_{2}$. However, UN has a maximum operating temperature $-500 \mathrm{~K}$ lower than $\mathrm{UO}_{2}$. This lower operating temperature is somewhat offset because the thermal conductivity of $\mathrm{UN}$ is about an order of magnitude higher than for $\mathrm{UO}_{2}$; however, fuel conductivity is not a major factor in HPS/HBS. Also, a UN core is smaller, causing a higher power density and thus higher temperature gradients. The other factor with using UN is that the fuel pin needs to remain sealed to prevent a loss of nitrogen. Based on these factors, UN may be best suited only for applications where low power is acceptable and low mass is the driving factor. There are additional fuel forms that look attractive for advanced versions of HPS/HBS. Carbide-based fuels have a high uranium loading, high conductivity, and high stability at elevated temperatures. The perceived problems with carbides are swelling and compatibility issues, which will require further testing. Cermet fuels may have the ability to operate at extremely high temperatures, which would allow a very high hydrogen exit 
temperature in HBS. The primary drawback of cermet fuel is the relatively low fuel loading, plus there are little recent test data. Also, cermet fuels may not be suitable for systems requiring much more than $1 \%$ burnup.

\section{Clad/Heatpipe}

The choice of cladding material essentially is limited to materials that have been tested with a specific fuel. For UN the clads considered are $\mathrm{Nb} 1 \mathrm{Zr}$ (with a Re liner) and Mo (possibly with Re liner or in Re alloy form). There is more knowledge about the behavior of $\mathrm{Nb} 1 \mathrm{Zr}$ than $\mathrm{Mo}$ for this type of application, and it is easier to use in fabrication. However, Mo has advantages both in heat transfer and neutronic performance. Mo has a higher melting point and a higher thermal conductivity, which allows higher powers. Neutronically, Mo is better than $\mathrm{Nb} 1 \mathrm{Zr}$ because $\mathrm{Nb} 1 \mathrm{Zr}$ has absorption resonances up to $10 \mathrm{keV}$, which impacts the nominal $\mathrm{k}_{\text {eff }}$ much more than the Mo resonances, which only go up to $1 \mathrm{keV}$. Also, the Mo resonances $<1 \mathrm{keV}$ are stronger than those for $\mathrm{Nb} 1 \mathrm{Zr}$, making Mo better for aiding in passive shutdown. Using $\mathrm{Nb} 1 \mathrm{Zr}$ clad as opposed to Mo causes a $\sim 1 \%$ decrease in nominal $\mathrm{k}_{\text {eff }}$ and a $\sim 2 \%$ decrease in $\Delta \mathrm{k}$ in water immersion. As a result, although $\mathrm{Nb1Zr}$ is of lower density than $\mathrm{Mo}$, an $\mathrm{Nb1Zr}$ clad core ends up weighing more to achieve the same neutronic performance. For $\mathrm{UO}_{2}$, the clads considered are Mo and $\mathrm{W}$. Molybdenum has a distinct advantage in mass because its density is almost a factor of two lower than $\mathrm{W}$. Tungsten has the advantage of going to higher temperatures, which is important in bimodal operation. Also, $W$ has stronger thermal resonances to aid in passive shutdown (although Mo can be alloyed with Re to achieve the same effect at lower mass), and $\mathrm{W}$ has higher strength. For example, if hoop stress was the limiting factor in choosing clad thickness, then $\mathrm{W}$ clad possibly could be more mass effective than Mo. Russian single crystal Mo alloys may be suitable for cladding for most potential fuel forms. For both HPS and HBS, the heatpipe material is specified to be the same as the clad to avoid having to bond dissimilar metals.

\section{Structure}

Just as the cladding material is somewhat driven by the choice of fuel, the structural materials are driven somewhat by the cladding material because it is desirable to avoid bonding between dissimilar metals. The considered structural materials, in order (in general) of increasing mass, operating temperature, strength, and thermal neutron absorption are stainless steel, $\mathrm{NblZr}, \mathrm{Mo}, \mathrm{W}$, and Re. The decision of which materials to use is driven by mass, temperature, strength, irradiation, and neutronic requirements. Also, structural materials chosen for the shield end of the core must consider the shielding effect of those materials.

\section{Interstitials}

In HPS, and to some extent in HBS (depending on how the hydrogen flow is channeled), there is a significant amount of unutilized interstitial void between pins. It is possible to utilize this void region to improve the neutronic and heat transfer characteristics of the system. Filling, or partially filling, the interstitial void aids in the neutronic design because it reduces the amount of water in the core during flooding. The positive influence of the filler material during water immersion becomes even greater if a thermal neutron absorber is present in the material. The interstitial void also can be used to aid in heat transfer. Filler material can increase the conductivity between pins and modules. The interstitials could be filled with any of the following metals: $\mathrm{Nb} \mathrm{Zr}, \mathrm{Mo}, \mathrm{W}$, or Re. These metals could be in the form of a cusp, a rod, or a metallic wool. If interstitial absorbers are needed for passive shutdown, it may prove mass effective to utilize the high thermal neutron absorptivity of ${ }^{10} \mathrm{~B}$ by either doping the metal with ${ }^{10} \mathrm{~B}$ or placing some $\mathrm{B}_{4} \mathrm{C}$ in holes in the metal. One additional way to improve thermal conductivity is to fill the vessel with a conducting fluid, possibly helium or lithium.

\section{Axial Reflector}

The baseline HPS design has $5 \mathrm{~cm}$ of BeO on each end of the fuel pin, and the baseline HBS design has $5 \mathrm{~cm}$ of $\mathrm{BeO}$ on the cold end. The axial reflector region is not worth much neutronically ( $<1 \%$ in $\mathrm{k}_{\mathrm{eff}}$ ), but the region also may be important in terms of shielding and providing a temperature buffer between the active core and the structure. If more shielding is required, or if $\mathrm{BeO}$ is found to be incompatible with the fuel or clad, then depleted fuel could be used instead. Also, $\mathrm{W}, \mathrm{Re}$, or $\mathrm{B}_{4} \mathrm{C}$ wafers could be used in this region as well.

\section{Radial Reflector}

Two materials have been considered for the radial reflector material - beryllium (Be) and beryllium oxide $(\mathrm{BeO})$. Be has a lower density, a higher thermal conductivity, and is easier to use in fabrication than $\mathrm{BeO}$. 
Contrarily, $\mathrm{BeO}$ can operate at higher temperatures and is more effective neutronically than $\mathrm{Be}$ because it produces a less thermalized spectrum and its macroscopic scatter cross section is larger at high energies. For the baseline HPS design, a Be radref would have to be $5 \mathrm{~cm}$ thicker than a $\mathrm{BeO}$ radref $(16 \mathrm{~cm}$ as compared to $11 \mathrm{~cm})$ to have the same reactivity worth, but the resulting radref mass would be about the same. However, because the Be radref would be larger, there would be an increase in shield and structural mass. Currently, the baseline material is $\mathrm{BeO}$, but to make a final decision, a design would have to be optimized separately for each material.

\section{Shield}

Neutron shielding is provided by lithium hydride $(\mathrm{LiH})$. If gamma shielding is required, then tungsten or some other high- $Z$ material will be used. If a gamma shield is used, then a thermal neutron absorber may be placed in front of the gamma shield to reduce neutron capture gammas. This could be done by using a layer of $\mathrm{B}_{4} \mathrm{C}$ or natural or enriched LiH.

\section{NUCLEAR ANALYSIS}

The nuclear analysis of the HPS/HBS systems has been performed with MCNP (Briesmeister, 1993). Detailed MCNP models have been constructed for each system that fully represent the conceptual designs. Figure 2, the core schematic of a typical HPS system, was actually generated by MCNP. The primary goal of the neutronics analysis has been to arrive at a system that is passively safe in all accident scenarios. The scenarios chosen for this analysis are: (1) core flooded, wet sand surround, control drums in, (2) core flooded, wet sand surround, radial reflector off, (3) core flooded, water surround, radial reflector off, and (4) core compacted, wet sand surround, radial reflector off.

Passive subcriticality is achieved by introducing low-energy neutron absorbers into the core and taking advantage of the neutron spectral shift associated with accident conditions. The disadvantage of adding the absorbers is that it increases the mass of the system because it is harder to achieve criticality under nominal conditions. For HPS/HBS, this mass increase may be from 40 to $80 \mathrm{~kg}$, depending on the design. For missions where 40 to $80 \mathrm{~kg}$ of mass savings could greatly enhance the mission and reentry is not possible after the reactor has operated, passive shutdown mechanisms could be employed that require active removal before operation. Options of this type could include: one or more in-core safety rods, retractable rods or wires from the interstitials, or partial fueling of the reactor in space. Of these options, retractable rods or wires probably would be the simplest, most mass effective, and most reliable.

The baseline HPS/HBS designs have been given the requirement of having a minimum clean/cold $k_{\text {eff }}$ of 1.03 and a maximum $\mathrm{k}_{\mathrm{eff}}$ of 0.99 for accident conditions. In general, each of the accident requirements is equally difficult to achieve, except for the reflector off/water surround, which results in a $\mathrm{k}_{\text {eff }}$ up to $5 \%$ lower than for wet sand surround. Because wet sand represents the worst case, additional analysis will have to be performed in which the sand/water mixture is varied. The current analysis uses a sand/water mixture that is about $2 / 3$ quartz.

A clean/cold $\mathrm{k}_{\text {eff }}$ of 1.03 allows a conservative margin for burnup reactivity, which is estimated to be $\sim 0.2 \% \Delta \mathrm{k}$ given $0.7 \%$ burnup, and the temperature defect reactivity, which is estimated to be $<1 \% \Delta \mathbf{k}$. It also may be desirable from a reliability standpoint to have enough excess reactivity to allow for one failed control drum on startup. One control drum has a worth of $\sim 2 \%$ (all six drums combined have a worth of $\sim 11 \%$ ). High drum worth is needed to ensure subcriticality in the water-immersion/reflector-on scenario.

Because of the detail of the MCNP models, each of the above accident scenarios can be simulated without smearing materials except for core compaction. To model core compaction, a smeared model of the core was generated. The smeared model calculated $\mathrm{k}_{\mathrm{eff}}$ within $1 \%$ of the detailed model. To simulate compaction, all of the core void was removed and the reactor vessel was shrunken in the radial direction accordingly. The possibility exists that a completely compacted core does not represent the worst case and that a small amount of water in the core will result in a higher reactivity. Future calculations will analyze these intermediate cases. Also, the likelihood of significant core compaction is extremely small because the fuel pins and heatpipes are in a configuration in which they are fit together as closely as possible. Therefore, compaction can arise only via 
deformation of the pins and heatpipes themselves. This makes the probability of significant compaction very small because the pins are filled with fuel (making them very hard to deform) and they vastly outnumber the heatpipes.

Another purpose of the neutronics analysis is shield design. The shield design depends largely on the dose requirements, the payload separation, and the reactor power level. Neutron shielding is provided by a lithium hydride shield. If necessary, gamma shielding will be provided by a tungsten or other high-Z shield, depleted fuel pellets on the shield end of the fuel pin, or a thick core support plate. A baseline shield has been modeled assuming a reactor power of $100 \mathrm{kWt}$, an allowable gamma dose rate of $5 \times 10^{4} \mathrm{rad} / \mathrm{yr}$, and a neutron dose rate of $10^{12} \mathrm{n} / \mathrm{cm}^{2} / \mathrm{yr}$ (1 MeV equivalent) at a 2-m-diameter dose plane located $10 \mathrm{~m}$ from the core centerline. In the baseline HPS/HBS designs, the heatpipes travel around the outside of the shield; therefore, radiation scatter off the heatpipes contributes to the dose. To estimate this effect, the heatpipes are modeled explicitly on the outside of the shield, and the contribution to the dose from radiation scattered off of the heatpipes is tallied. In most cases, the dose caused by scattering off the heatpipes is about an order of magnitude below the dose that travels straight through the shield. The thicker the shield, the more important the scatter off the heatpipes becomes. Heatpipe scatter does not appear to be an issue for typical dose requirements and thermal power.

One additional function of the neutronics calculations is to provide power density data to the heat transfer model. A code has been written to transform the tallies from the MCNP output file into an input file for the heat transfer code HBSHT, which will be described below. The peak to average power density ranges from 1.3 to 1.4 , depending on the design. It may be desirable to flatten the power distribution by varying the concentration of absorbers in the interstitials.

\section{THERMAL ANALYSIS}

A three-dimensional (3D) code, HBSHT, has been written to analyze the heat transfer and thermal hydraulic characteristics of HPS and HBS. The code divides each fuel pin into 19 nodes per axial level -6 clad and 13 fuel. The heat generation in the fuel is spatially defined by the MCNP output. The heatpipes are represented similar to the fuel clad, with a constant temperature boundary condition imposed on the inner surface. The temperature on the inside of the heatpipe depends on the type of heatpipe and the heat flux. The core is adiabatic on the top and bottom boundaries (except when propellant is flowing) and is surrounded radially by a hexagonal vessel. The vessel is radiatively coupled to the core on the inside. The outside of the vessel can be either adiabatic or radiatively coupled to the radial reflector. HBSHT includes temperature-dependent properties for several reactor materials and for hydrogen. HBSHT has been benchmarked with several hand calculations.

Three different conductivity factors are used as code input: fuel-to-clad conductivity, pin-to-pin conductivity within module, and pin-to-pin conductivity between modules; these factors will depend on the manufacturing technique used and whether interstitial fill material is used. The conductivity factors are defined in terms of degrees contact between surfaces, with a value of zero representing radiation only. In addition, the conductivity of an interstitial fill fluid can be specified. For the fuel-to-clad conductivity, there is also an option of adding a helium gap. Also, the radial conductivity of the heatpipe wall can be varied, which allows the simulation of the proposed vacuum gap between the heatpipe and the heatpipe liner in HBS.

To model HBS propulsion, hydrogen is flowed through the interstitials between the pins. The code offers the option of flowing though all of the interstitials or blocking flow in interstitials next to the vessel and/or heatpipes. The flow solution is one-dimensional through each interstitial channel and is iteratively coupled to the 3D heat transfer solution. The heat transfer coefficient and friction factor are determined by standard laminar and turbulent channel flow relations. For moderate thrust systems $(-100 \mathrm{~N})$, the flow is laminar.

The primary results of HBSHT are the maximum and average temperatures of each material, the maximum and average radial and axial heatpipe heat fluxes, and the total power to the heatpipes and the vessel. If the propulsion mode is analyzed, the output also includes the total power to the propellant; the maximum, minimum, and mean propellant outlet temperature; and the maximum and average Reynolds Number and pressure drop. 
HBSHT models the entire core, as opposed to a symmetric section, to simulate the effect of a failed heatpipe fully. The code includes the option of failing each heatpipe one at a time and listing the results in tabular form so that the worst-case heatpipe failure is identified. This information then can be used to improve the orientation of the modules and reduce the impact of the worst-case heatpipe failure.

\section{RESULTS}

A summary of five core designs is given in Table 1. Results for several other designs are presented in the aforementioned companion paper (Houts, 1996). The first three designs, HPS-7UN, HPS-7UCN, and $\mathrm{HPS}^{-7 \mathrm{UO}_{2}}$ (the 7 represents the number of rows of pins), are meant to compare the relative merits of each fuel form. The fourth design, $\mathrm{HBS}-10 \mathrm{UO}_{2}$, is meant for comparison with $\mathrm{HBS}-7 \mathrm{UO}_{2}$ to demonstrate how power can be increased without an increase in reactor mass by using a larger number of smaller modules. The final design, $\mathrm{HBS}-10 \mathrm{UO}_{2}$, is the baseline bimodal design. This shows the impact of going to a bimodal design on mass and power output. The big drop in thermal performance is caused by the vacuum gap between the heatpipe liner and the heatpipe. If more thermal power is required, it should be possible to enhance heat transfer while retaining the desired effects of the vacuum gap - to prevent hydrogen ingress into the heatpipes and to prevent overcooling of the heatpipe in propulsion mode. None of the designs presented have been optimized fully. Mass estimates are given without the

TABLE 1. Summary of Parameters for 4 HPS and 1 HBS Core Designs.

\begin{tabular}{|c|c|c|c|c|c|}
\hline Design Name & HPS-7UN & HPS-7UCN & HPS-7 $\mathrm{UO}_{2}$ & HPS-10UO & HBS- $10 \mathrm{UO}_{2}$ \\
\hline $\begin{array}{l}\text { Number of Heatpipes (modules) } \\
\text { Number of Fuel Pins } \\
\text { Core Hex Flat to Flat }-\mathrm{cm} \\
\text { Active Core Height }-\mathrm{cm} \\
\text { Radref Thickness }-\mathrm{cm} \\
\text { Pin Outer Diameter }-\mathrm{cm} \\
\text { Pin } / D \text { (Clad Thickness/Outer Diameter) }\end{array}$ & $\begin{array}{c}30 \\
138 \\
19.7 \\
32 \\
11 \\
1.50 \\
.050\end{array}$ & $\begin{array}{c}30 \\
138 \\
19.7 \\
33 \\
11 \\
1.50 \\
.050\end{array}$ & $\begin{array}{c}30 \\
138 \\
26.2 \\
36 \\
12 \\
2.00 \\
.050\end{array}$ & $\begin{array}{c}57 \\
270 \\
25.7 \\
36 \\
12 \\
1.40 \\
.050\end{array}$ & $\begin{array}{c}57 \\
270 \\
25.7 \\
42 \\
11 \\
1.40 \\
.050\end{array}$ \\
\hline $\begin{array}{l}\text { Fuel Material ( } 93 \% \text { enriched) } \\
\text { Clad Material } \\
\text { Vessel / Slat Material } \\
\text { Interstitial Fill ( } 55 \% \text { void) }\end{array}$ & $\begin{array}{l}96 \% \mathrm{TD} \text { UN } \\
\mathrm{Nb} 1 \mathrm{Zr} / \mathrm{Re} \\
\mathrm{Mo} \\
\mathrm{Nb} \% \mathrm{~B} 4 \mathrm{C}\end{array}$ & $\begin{array}{l}13 \mathrm{~g} / \mathrm{cc} \mathrm{UCN} \\
\mathrm{Mo} 3 \mathrm{Nb} \\
\mathrm{Mo} 3 \mathrm{Nb} \\
\mathrm{Mo} 10 \% \mathrm{~B} 4 \mathrm{C}\end{array}$ & $\begin{array}{c}85 \% \mathrm{TD} \mathrm{UO}_{2} \\
\mathrm{Mo} 3 \mathrm{Nb} \\
\mathrm{Mo} 3 \mathrm{Nb} \\
\mathrm{Mo} \% \mathrm{~B} 4 \mathrm{C}\end{array}$ & 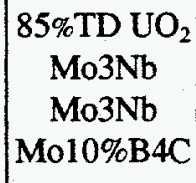 & $\begin{array}{l}85 \% \mathrm{TD} \mathrm{UO}_{2} \\
\mathrm{~W} \\
\mathrm{Mo} 10 \mathrm{Re} \\
\text { none }\end{array}$ \\
\hline $\begin{array}{l}\text { U-235 Loading - kg } \\
\text { Radref Mass - kg } \\
\text { Reactor Mass (inc. radref) - kg } \\
\text { Shield Mass @ 100kWt (dose req. in text) - kg } \\
\text { Mass (Core, Reflector, Shield, Heat Transport) }\end{array}$ & $\begin{array}{c}75 \\
119 \\
255 \\
110 \\
365\end{array}$ & $\begin{array}{l}71 \\
125 \\
256 \\
110 \\
366\end{array}$ & $\begin{array}{c}96 \\
174 \\
374 \\
125 \\
499\end{array}$ & $\begin{array}{c}94 \\
180 \\
372 \\
125 \\
497\end{array}$ & $\begin{array}{l}115 \\
171 \\
415 \\
125 \\
540\end{array}$ \\
\hline $\begin{array}{l}\text { k-eff, Drums Out, Beginning of life (BOL) } \\
\text { k-eff, Drums In, BOL } \\
\text { k-eff, Immersed, Drums In, BOL } \\
\text { k-eff, Immersed, Wet sand replace radref,BOL } \\
\text { k-eff, Immersed, H2O replace radref, BOL }\end{array}$ & $\begin{array}{l}1.035 \\
0.917 \\
0.981 \\
0.984 \\
0.941\end{array}$ & $\begin{array}{l}1.030 \\
0.919 \\
0.974 \\
0.986 \\
0.943\end{array}$ & $\begin{array}{l}1.033 \\
0.921 \\
0.991 \\
0.989 \\
0.947\end{array}$ & $\begin{array}{l}1.030 \\
0.920 \\
0.990 \\
0.992 \\
0.943\end{array}$ & $\begin{array}{l}1.032 \\
0.923 \\
0.992 \\
0.990 \\
0.940\end{array}$ \\
\hline Peak Bumup/yr per $100 \mathrm{kWt}$ & $0.070 \%$ & $0.074 \%$ & $0.057 \%$ & $0.060 \%$ & $0.048 \%$ \\
\hline $\begin{array}{l}\text { Max HP radial heat flux per } 100 \mathrm{kWt}-\mathrm{W} / \mathrm{cm}^{2} \\
\text { Max HP axial heat flux per } 100 \mathrm{kWt}-\mathrm{kW} / \mathrm{cm}^{2}\end{array}$ & $\begin{array}{l}27 \\
2.3\end{array}$ & $\begin{array}{l}27 \\
2.5\end{array}$ & $\begin{array}{l}20 \\
1.4\end{array}$ & $\begin{array}{l}15 \\
1.3\end{array}$ & $\begin{array}{l}11 \\
1.5\end{array}$ \\
\hline \multicolumn{6}{|c|}{ Maximum Thermal Power - $\mathrm{kWt}$ (nominal/failed heatpipe). } \\
\hline $\begin{array}{l}10 \text { deg. solid conduction between modules } \\
\text { Radiation only between modules }(\varepsilon=0.5) \\
\text { Helium Interstitial Fill } \\
\text { Lithium Interstitial Fill }\end{array}$ & \begin{tabular}{|l|}
$360 / 150$ \\
$330 / 75$ \\
$330 / 125$ \\
$410 / 210$ \\
\end{tabular} & $\begin{array}{l}680 / 290 \\
610 / 145 \\
600 / 255 \\
750 / 420 \\
\end{array}$ & $\begin{array}{l}620 / 250 \\
510 / 170 \\
510 / 210 \\
660 / 330 \\
\end{array}$ & $\begin{array}{l}1220 / 460 \\
1020 / 300 \\
1020 / 370 \\
1330 / 640 \\
\end{array}$ & $\begin{array}{c}125 / 110 \\
120 / 95 \\
\text { N/A } \\
\text { N/A }\end{array}$ \\
\hline
\end{tabular}


power conversion system. The estimated mass of a $5-\mathrm{kWe}$ thermoelectric power conversion system is $100 \mathrm{~kg}$, resulting in several options with a total mass (excluding power conditioning) of $<600 \mathrm{~kg}$. The maximum thermal power for nitride fueled cores is based on a maximum UN fuel temperature of $1600 \mathrm{~K}$. For oxide and carbonitride cores, the maximum thermal power is based on a maximum clad temperature of $1800 \mathrm{~K}$. Each case assumes that there is the equivalent of 10 degrees contact between the pins within a module. Results are presented for four options of module to module thermal coupling: none (radiation only), solid bonding (equivalent to 10 degrees of contact), helium bond, and lithium bond.

The failed heatpipe result assumes that the worst-case heatpipe has failed for each respective design. The large reduction in maximum power caused by a failed heatpipe is the result of a large local temperature increase. The effect of the failed heatpipe is felt only by the adjacent modules; thus, if there is more than one failed heatpipe, the maximum power output will not change significantly unless adjacent heatpipes fail. The maximum thermal power shown in Table 1 also assumes that the power profile is flattened. If no attempt is made to flatten the power profile, the maximum attainable power drops by $\sim 20 \%$ because of peaking. On Table 1 , the peak burnup and heatpipe heat fluxes are normalized to $100 \mathrm{kWt}$. These numbers can be used to predict the power level at which burnup and/or heat flux limitations become an issue.

Propulsion results for $\mathrm{HBS}-10 \mathrm{UO}_{2}$ are not listed in Table 1. The baseline HBS flow area is $62 \mathrm{~cm}^{2}$, and the heat transfer area is $\sim 5 \mathrm{~m}^{3}$. When hydrogen is flowed through the interstitials, the mixed mean outlet temperature is within $100 \mathrm{~K}$ of the peak clad temperature. If flow is restricted next to the heatpipes and the vessel (which reduces the flow area by about a factor of 3 ), this difference drops to $60 \mathrm{~K}$. In addition, other passages could be orificed to make this delta even smaller. When the $\mathrm{HBS}-10 \mathrm{UO}_{2}$ design is operated in propulsion mode at a power of $350 \mathrm{kWt}$ and a flow rate of $6.8 \mathrm{~g} / \mathrm{s}$ (corresponding to a thrust of $50 \mathrm{~N}$ ) and flow is restricted next to heatpipes and the vessel, $100 \mathrm{kWt}$ goes to the power conversion subsystem and $220 \mathrm{kWt}$ goes to the hydrogen (the rest is lost to the surroundings). In this case, the maximum clad temperature is $2130 \mathrm{~K}$ and the mixed mean outlet temperature is $2070 \mathrm{~K}$. Even with two thirds of the flow area blocked, the peak and average Reynolds numbers are only 530 and 190 , respectively. Also, the pressure drop is on the order of a few kilopascals. One other interesting result of the propulsion mode results is that there is almost no heat flux into the heatpipe at the cold end, whereas the heat flux is doubled (as compared to power mode conditions) at the hot end. This result would be much worse if not for the vacuum gap between the heatpipe and the heatpipe sleeve.

\section{CONCLUSIONS}

This paper discusses methods and results of the nuclear and thermal analysis of two fission-powered concepts: the HPS, which provides power only, and the HBS, which provides both power and thermal propulsion. Results of this study indicate that the HPS and HBS systems can provide substantial levels of power and propulsion at low mass with a high degree of safety and reliability. The systems have been designed to utilize existing technology and facilities, which will make the development cost relatively low.

\section{Acknowledgments}

The authors wish to thank the numerous individuals within the space power community who have contributed comments and suggestions related to the HPS/HBS concepts. The designs have benefited greatly from this input.

\section{References}

Briesmeister, J.F. (1993), "MCNP - A General Monte Carlo N-Particle Transport Code." LA-12625-M, Los Alamos National Laboratory, Los Alamos, New Mexico.

Houts, M.G., D.I. Poston, and W.A. Ranken (1996), "Heatpipe Space Power and Bimodal Systems," in Proc. 13th Symposium on Space Nuclear Power and Propulsion, CONF-960109, M.S. El-Genk, ed., American Institute of Physics, New York, AIP Conf. Proc. No. TBD. 